\title{
SALUD SEXUAL Y REPRODUCTIVA EN ESTUDIANTES DE JORNADA NOCTURNA
}

Luz Adriana Abril G., Bibiana Paola Álvarez B., Angélica Maria Cortes A., Diana Milena Cruz M., Andrea Hernández C., Natalia Ximena Palacios C.*

\section{Resumen}

Esta investigación plantea el siguiente objetivo general: evaluar la modificación en conocimientos atribuibles a un taller educativo sobre salud sexual y reproductiva en una población especifica y como objetivos específicos:

1. Determinar el nivel de conocimientos de los estudiantes del centro educativo SUA antes y después de implementado el taller educativo.

2. Comparar el nivel de conocimientos en el pretest y postest con el fin de identificar cambios atribuibles al taller educativo. Para llevar a cabo este taller se realizaron sesiones de instrucción de una hora y media cada una donde se tuvieron en cuenta temas como: autoestima, autoimagen, salud sexual y reproductiva, genitalidad, sexo, sexualidad, derechos sexuales y reproductivos y planificación familiar. La metodología empleada fue inicialmente una dinámica de sensibilización posteriormente exposición con vídeo beam y para el tema de planificación familiar técnica demostrativa; al finalizar este se aclararon dudas y se respondieron preguntas, para evaluar la modificación en conocimientos se tomó como base un pretest y postest con las mismas preguntas, en el resultado de este taller se encontró un incremento en las respuestas positivas especialmente en temas como planificación familiar a preguntas: ¿el implante hormonal norplant se coloca?, se encontró un incremento del 52,77\% lográndose al realizar una medición indirecta un impacto del $\mathbf{2 8 , 7 2 \%}$. Es importante tener en cuenta que una de las limitaciones de esta investigación fue el tiempo que no permitió medir la fijación de conocimientos en al población objeto de estudio con un postest a mediano y largo plazo. Palabras claves: Taller educativo, salud sexual y reproductiva, adolescentes (salud sexual y reproductiva), métodos de planificación familiar, derechos sexuales y reproductivos, concepto de salud sexual y reproductiva, impacto taller educativo salud sexual, estudio antes y después.

\section{Introduccilón}

La necesidad de educación en salud sexual y reproductiva evidenciada en estadísticas encontradas en el DANE que nos dice que, en el año 2001 fueron 1.570 partos de adolescentes, Profamilia reporta que el 19\% de las adolescentes entre 15-19 años están embarazadas o lo han estado alguna vez, y la Secretaría de Salud que de 160.000 embarazos en Bogotá 33.000 terminan en aborto, estos entre otras cifras.

Para este fin se tomó una población de adolescentes en etapa tardía y adultos jóvenes con edades entre 1624 años (se definen así según resolución 0412 capitulo 6 del Ministerio de Salud).

Estudiantes de VII Semestre de Enfermería Fundación Universitaria de Ciencias de la Salud.

** Este trabajo fue realizado bajo la tutoría del Dr. Guillermo Sánchez, Médico Ginecoobstetra de la Clínica del Country.
Se realizó un pretest en el cual se identificaron falencias de conocimientos en temas relacionados con sexo, sexualidad, planificación, derechos sexuales donde se trataron las variables de autoestima, autoimagen, salud sexual y reproductiva, derechos sexuales, métodos anticonceptivos como son: los naturales, de barrera, hormonales y definitivos, tomándose estos tópicos como base se diseño un taller el cual se aplica a dicha población.

Para el análisis de resultados se realiza un postest con las mismas preguntas dando origen a un trabajo antes y después.

\section{Materiales y métodos}

Tipo de estudio: de intervención antes y después en el que el grupo investigador identificó la modificación en conocimientos por medio de un pretest y postest sobre salud sexual y reproductiva en los estudiantes del centro educativo ya mencionado. 
Para la recolección de datos se utilizó un cuestionario cerrado de selección múltiple el cual tuvo 30 preguntas con opciones A, B, C y D.

Se hizo una comparación pretest y postest en términos porcentuales, la tabulación se realizó en Excel basándose posteriormente a stata 6.0 programa estadístico que transforma información numérica a porcentajes

\section{Resultados}

En las variables autoestima- autoimagen:

\section{Preguntas:}

- $1 \mathrm{AE}$ quererme es: se incrementaron las respuestas positivas en $9,51 \%$

- 2AE demuestro mi autoestima cuando: se incrementaron las respuestas positivas en 18,83\%

- 3AI considera que sus genitales son: se encontró una disminución en las respuestas correctas en -11,76\%

- 4AI mi autoimagen mejora cuando: se incrementaron las respuestas positivas en $28,7 \%$ (Figura 1).

En las variables sexo, salud sexual, sexualidad y derechos sexuales:

\section{Preguntas:}

- 5S sexo es: se incrementaron las respuestas positivas en $32,28 \%$

- 7SL sexualidad es: se incrementaron las respuestas positivas en $39,02 \%$

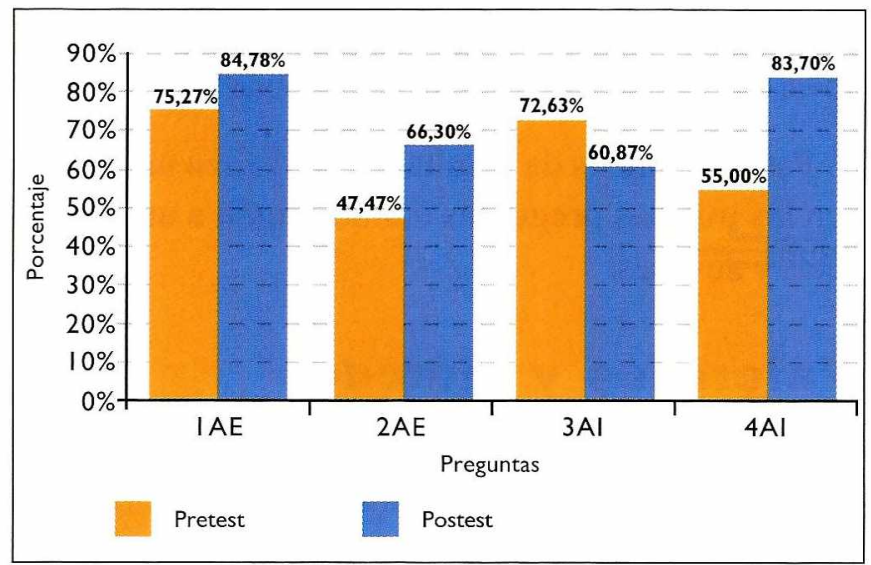

Figura I. Modificación de conocimientos en variables autoestima y autoimágen.
- 8SS la salud sexual implica: se encontró una disminución en las respuestas correctas en -1,2\%

- 11DSR la constitución habla sobre derechos sexuales: se incrementaron las respuestas positivas en $29,78 \%$ (Figura 2).

En los variables métodos de planificación familiar:

\section{Preguntas:}

- $17 \mathrm{PF}$ dónde guardar el preservativo: se incrementaron las respuestas positivas en 49,95\%.

- $22 \mathrm{PF}$ son métodos de planificación familiar naturales, excepto: se incrementaron las respuestas positivas en $39,18 \%$

- $25 \mathrm{PF}$ el uso prolongado de las píldoras puede llevar a: se incrementaron las respuestas positivas en $40,59 \%$

- 26PF la píldora es efectiva cuando: se incrementaron las respuestas positivas en $40,6 \%$

- 29PF el implante hormonal se coloca: se incrementaron las respuestas positivas en $52,77 \%$

- 30PF son métodos definitivos de planificación: se incrementaron las respuestas positivas en $31,68 \%$ (Figura 3)

Impacto: al realizar la medición indirecta del impacto se encontró que las respuestas contestadas correctamente en el pretest fueron el $41,84 \%$ y en el postest el $70,76 \%$, dando como resultado un 28,92\% notándose una modificación de conocimientos positiva. (Figura 4).

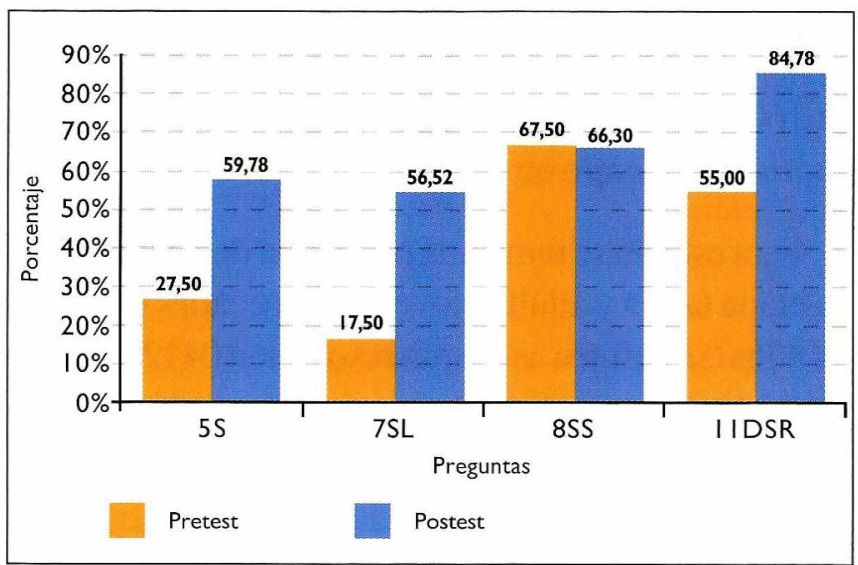

Figura 2. Modificación de conocimientos en sexo, sexualidad, salud sexual y derechos sexuales. 


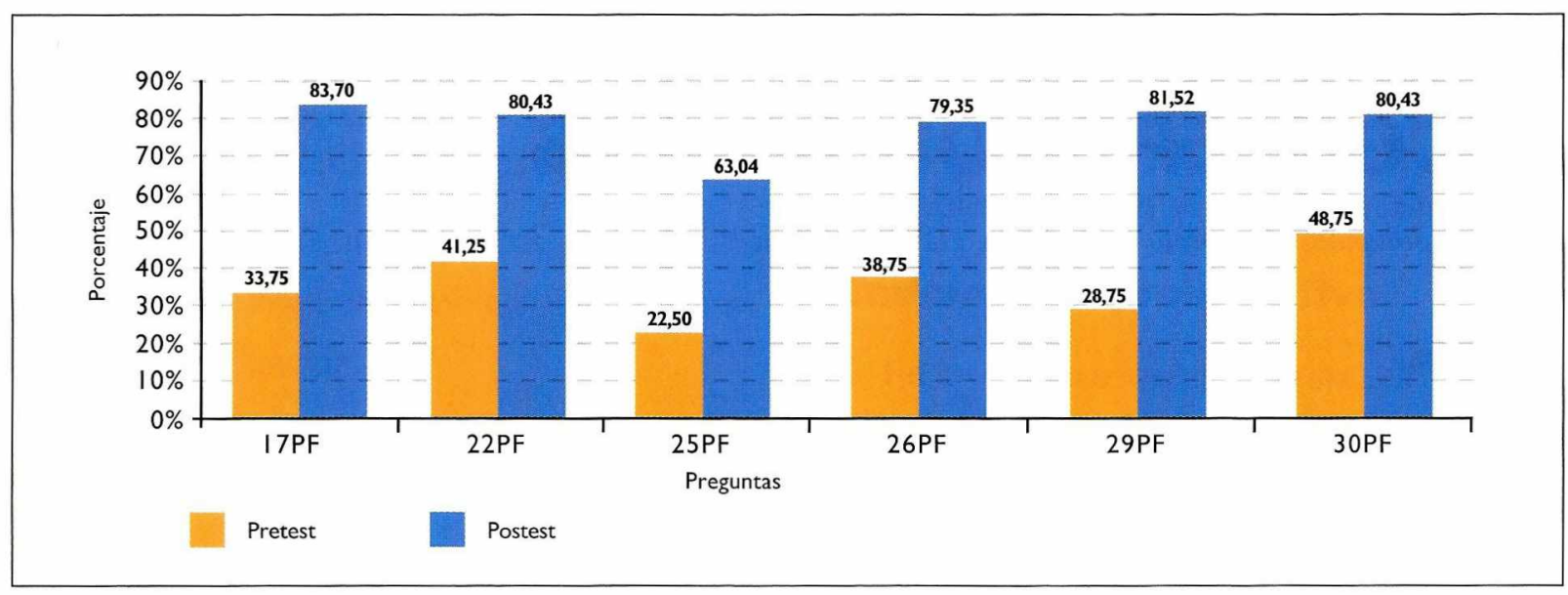

Figura 3. Modificación de conocimientos en planificación familiar.

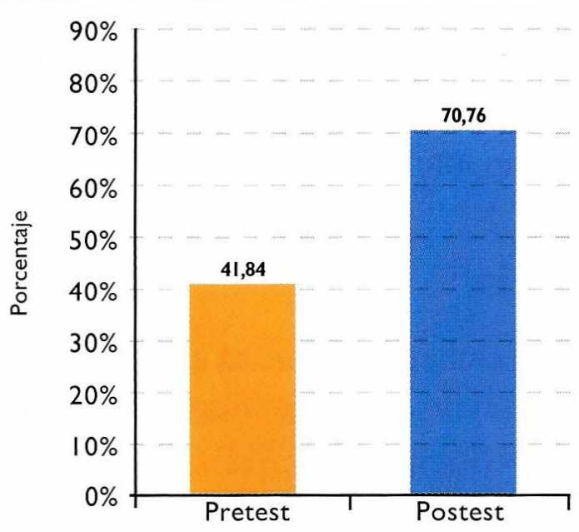

Figura 4. Medición indirecta del impacto.

\section{Conclusiones}

La modificación en conocimientos en la población objeto de estudio acerca del tema salud sexual y reproductiva fue positiva lo cual se vio reflejado en la comparación de los resultados obtenidos en las pruebas pre y postest.

Una de las limitaciones de esta investigación fue el tiempo el cual no permitió la realización de un postest a mediano y largo plazo, lo cual hubiese facilitado medir los cambios en la fijación de conocimientos en la población objeto de estudio.

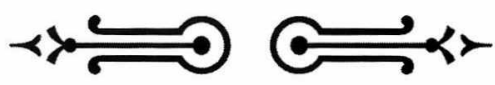

